\title{
ROLE OF RESPONSIVE FEEDING ON NUTRITIONAL STATUS OF CHILDREN WITH CEREBRAL PALSY
}

\author{
Sushama Kanan ${ }^{1}$ \\ Md Jahangir Alam ${ }^{2}$
}

\begin{abstract}
Under nutrition is common in children with cerebral palsy $(C P)$ due to oromotor dysfunction and feeding difficulties. Responsive feeding is a growing concern in nutrition field as a potential intervention for caregiver's behaviour change during feeding. This study was designed to identify the feeding style of caregiver and the role of responsive behaviour on food refusal and nutritional status of young children with CP. This was a cross-sectional mix method study. Participants were children with CP aged between 18-36 months. 66 caregiverchildren were selected as quantitative sample and 11 mothers were included in two focused group discussions for qualitative data. Children's feeding session for one main meal was videotaped at a rehabilitation centre. Feeding styles were coded as active and responsive behaviour which was further categorized into positive and negative behaviour. Nutritional status was measured as weight for age $z$ scores. Caregivers mostly used active behaviour than responsive and more positive behaviour than negative. The relation between feeding style and food refusal was found and negative behaviour was related with increased food refusal. Significant relationship was found between caregiver's active and positive behaviour and child's active behaviour. More than half of the children with CP were underweight for their age. No significant relation appeared between weight for age z score and caregiver's feeding style.
\end{abstract}

Keywords: Responsive feeding, Nutrition, Cerebral Palsy, Oro-motor dysfunction, Feeding difficulties, Food refusal

\section{Background of the Study}

Under nutrition is highly prevalent in low-income and middle-income countries, resulting in substantial increases in mortality and overall disease burden

1 Senior Research Associate, James P Grant School of Public Health, BRAC University. Email: sushama.kanan@gmail.com

2 Assistant Professor, Dept. of Communication Disorders, University of Dhaka, Dhaka-1000, Bangladesh. Email: jahangiralam@du.ac.bd

Social Science Review [The Dhaka University Studies, Part-D], Vol. 38, No. 1, June 2021

DOI: https://doi.org/10.3329/ssr.v38i1.56532 
(ICDDR'B, 2011). In children under nutrition has a serious and long-term effect on developing physical health, mental health, productivity, human capital, and it might also affect future generation (Victora, et al., 2008), overall income and economic growth of the country (Shekar, Heaver \& Lee, 2006).

Under nutrition is a serious public health problem in Bangladesh, mostly in children and women (Akhtaruzzaman, Khan \& Islam, 2013). Children aged 6-23 months have the highest risk of wasting, stunting and underweight which are major indicators for measuring under nutrition (Muiruri et al., 2012).

Adequate nutrition is very important and an essential right for all children including children with disabilities, as stated in the Convention on the Rights of the Child (UNICEF, 2013). Nutrition and disability are intimately related, and both are global development priorities (UNICEF, 2013). The nutritional needs of children with disabilities are different from their non-disabled counterpart and the reason behind poor nutrition varies (WHO/World Bank, 2011).

Cerebral Palsy (CP) is one of the most common childhood physical disabilities, defined as a group of disorder of development of movement and posture, which causes activity limitation. It is a non-progressive brain disorders caused by brain injury during birth or just after birth and persists through the lifespan (Rosenbaum et al., 2007). In addition to motor impairment, the other common difficulties found in $\mathrm{CP}$ are hearing difficulties, vision difficulties, language/speech difficulties, epilepsy, behaviour disorder, intellectual disability etc. (Rosenbaum et al., 2007).

Majority of children with CP have oro-motor dysfunction (9 to 90\%) which leads to chewing and swallowing difficulties (Reilly, Skuse \& Poblete, 1996). Literature showed that there is an association between feeding difficulties in children with CP and their poor food intake and poor nutritional status (Reilly et al., 1996; Sullivan et al., 2000; Fung et al., 2002; Odding, Roebroeck \& Stam, 2006). Oral motor dysfunction and feeding problem in children with CP appeared in early age and disturbed growth and nutritional status (Hou, Fu, Zhao, Lan \& Zhang, 2004).

Many studies of children with cerebral palsy (CP) have reported evidence of growth impairment or micronutrient deficiency (Hals et. al., 1996 cited in Tompsett, Yousafzai \& Filteau, 1999). Under nutrition is prevalent in children with $\mathrm{CP}$ which hamper their growth, cerebral function, increase children's 
irritability, decrease their motivation for other developmental activities (Sullivan et al., 2000). Children with mild to severe CP whether they can self-feed or not mostly depend on their caretaker for their feeding (Ferluga et al., 2013).

To achieve and maintain proper nutrition, health and development of children, proper feeding practices are necessary during infancy and childhood. Inappropriate feeding practices can lead to negative affect for growth, development and survival of infants and children, especially in developing countries (Kumar, Goyel, Mittal \& Mishra, 2006). Generally, responsive feeding defined as being sensitive to infant's and children's hunger and satiety cues while feeding infants directly and assisting older children when they feed themselves (UNICEF, 2011). A framework of responsive feeding and care conceptualized it as a three-step process: " $l$ ) the child signals requests through motor actions, facial expressions, or vocalizations; 2) the caregiver recognizes the signals and responds promptly in a manner that is emotionally supportive, contingent on the signal, and developmentally appropriate; and 3) the child experiences a predictable response to signals" (Black \& Aboud, 2011). Responsive feeding behaviours may include active physical help and verbalization during feeding, role-playing, persistence, and positive feeding strategies. Evidence shows that parental intrusiveness dominates parent-child interaction and causes lack of reciprocity which precedes early feeding difficulties (Moore, Akhter \& Aboud, 2005). It leads to poor growth of child.

\section{Literature Review}

In 2005 an analysis based on the WHO Child Growth Standards by UN regions and sub regions shows that $20.2 \%$ of children under 5 in all developing countries are under weight. The most recent Bangladesh national nutrition survey in 2011 shows that among children $<5$ years the prevalence of stunting is about $40.2 \%$ for both girls and boys, wasting $25.3 \%$ in girls and $22.3 \%$ in boys and underweight $45 \%$ in both boys and girls (Akhtaruzzaman et al., 2013). Though there is no exact data of prevalence rate of CP in Bangladesh, but in 2011 WHO/World Bank estimated $31 \%$ prevalence rate of disability in Bangladesh. Studies showed that under nutrition occurs at a high prevalence rate among children with mental retardation, autism, neurological difficulties, and the prevalence increases with cerebral palsy and children with feeding difficulties (Sánchez-Lastres, EirísPuñal, Otero-Cepeda, Pavón-Belinchón \& Castro-Gago, 2003; Shabayek, 2004; 
Yousafzai, 2003). Yousafzai (2003) found from their cross-sectional study in India that children with feeding difficulties were significantly malnourished than children without difficulties. This finding established that children with feeding difficulties have more chance to be malnourished though it included different types of disabilities who had feeding difficulties.

To start early intervention for preventing under nutrition in infant and children, WHO and UNICEF have developed evidence-based guideline principle for complementary feeding promoting appropriate feeding practices (Saha et al., 2008). This guideline considers importantly not only what foods are given but also how they are given. These guiding principles identify responsive feeding as a part of appropriate feeding practices (UNICEF, 2010).

As a result, style of feeding is getting considerable attention regarding its positive role on acceptance of food, dietary intake, child nutrition and health outcomes and it is particularly important in low resource setting where enhanced caring attitude can maximize existing food sources (Ha et al., 2002 and Bentley, Wasser \& Creed-Kanashiro, 2011). These feeding behaviours are embedded in responsive parenting which is contextual and depends on culture (Black \& Aboud, 2011). For example, In India and other developing countries, mothers play a vital role in childcare and feeding practices (Bhandari et al., 2004). Responsive feeding practices generally incorporate the component of care giving that are known to promote physical, mental, and social development (Engle et. al., 2000 cited in Moore et.al. 2005). Additionally, responsive feeding helps to develop constant positive interaction between mother-child (Horta, Bahl, Martines \& Victora, 2007). Responsive feeding becomes very much important for children's nutrition because according to UNICEF conceptual framework in addition to food security, health care services and healthy environment, feeding with care becomes important for survival for the child (Ha et al., 2002).

A study conducted by Ha et al. in 2002 aimed to find out styles of feeding among 12 or 18 months old rural Vietnamese children. They observed video of forty mother/child pairs during two feeding episodes. They coded caregiver and child behaviours at the level of the intended bite to assess caregiver's behaviour and the child's interest and acceptance of food. Their result showed caregiver provided physical help to eat almost all the time for younger children, about $70 \%$ of time among 18 months old and verbalized during 30\% of intended bites whereas half of these verbalizations were responsive in tone or words. They 
concluded positive caregiver behaviours were associated with higher child's acceptance of food and non-responsive behaviours were associated with child's rejection of food. Although the researchers could not certainly decide whether there was any reverse causality or not.

A systematic review was conducted by Bentley et al. in 2011. They included 21 studies focused on responsive feeding exposure and children under nutrition in lower middle-income countries. Most studies included children aged <36 months as this is the critical time for future development. They found promising evidence that positive caregiver verbalization encourages the child to accept the food. Only few studies intended to see the isolated effect of responsive feeding on children's nutrition, and it found positive association but to determine the significance of the evidence more research should be conducted. This review felt a necessity of further research on consensus on the definition and measurement of responsive feeding, longitudinal studies that begin early in infancy, and randomized controlled trials that isolate the effect of RF on child under nutrition.

Research by Engle et al. in 2011 aimed to examine responsive feeding as nutrition intervention and its implication in policy and program implementation. They reviewed policy from international agencies and high-income countries and found inclusion of responsive feeding in nutrition intervention. Analysing the reason of this inclusion reveals that feeding problem is identified as a major concern among health workers and caregivers. Parents are concerned about children's food refusal, intermittent eating, other feeding difficulties and sometimes mealtime behaviour become more sensitive than other growth. Finally, the responsive feeding messages are positive and effective, and parents can get result trying the recommendation and feedback loop is short.

Literature on effect of responsive feeding specific in children with CP is limited in subcontinent territory, however few studies reported on feeding practices, caregiver's role, and nutritional status of children with $\mathrm{CP}$ in a limited range. One study (Adams et al., 2012) has been done in Bangladesh on children with CP on feeding training of the caregiver. This study recruited 37 children aged 1-11 years old with moderate to severe CP. They found significant improvement in children's respiratory health, cooperation during feeding and overall mood of both caregiver and child but growth improvements were inconsistent. 


\section{Justification of the Study}

Feeding difficulties are one of the most common difficulties among children with $\mathrm{CP}$ and turns out cause of poor nutritional status for these children. This is not only affecting children's health but also results in stressful mealtimes, chronic malnutrition, respiratory disease, reduced quality of life for caregiver and child, and early death (Adams et al., 2012). Literature on responsive feeding in typically developing children shows that mother's responsiveness to interpret child's signal and responds to it stimulates child to behave actively during feeding (Moore et al., 2005). Children with CP has less self-feeding skill compared to their non-disabled partner which makes them dependent upon caregiver for feeding. So, reliance on caregiver makes this group suitable cohort who can be benefited from responsive feeding practices of caregiver for better nutrition. Additionally, limited evidence is available on the nutritional status of these children in developing countries. Evidence suggests that poor composition of food rather than total calorie intake is an important contributing factor for nutritional status of children with physical disability (Neyestani et al., 2010) as well as their feeding difficulties put them at additional nutritional risk (Tompsett, Yousafzai, \& Filteau, 1999). So, this study intends to look at mothers' or caregivers' responsive feeding skills and explore nutritional status of their CP children.

\section{Objectives of the Study}

The general objective of this study is to determine the role of responsive feeding on nutritional status of children with cerebral palsy.

The specific objectives are:

1. To determine the patterns of caregiver and child feeding styles in young children with $\mathrm{CP}$.

2. To observe caregiver's response to child's feeding cues and its effects on refusal of food.

3. To determine the association between responsive feeding practices and children's nutritional status.

4. To understand caregivers' perception about how their feeding practices affect their children, particularly nutrition, and caregiver's challenges. 


\section{METHODS}

\section{Study Design}

This study was a cross sectional study where a mix method (triangulation design) was used. A quantitative study was carried out as the main method to identify the characteristics of the feeding practices of caregiver. Caregiver's perception about how they feed the child and what difficulties they face while feeding was explored through focus group discussion with them.

\section{Study site}

The study was conducted at paediatric unit in Center for Rehabilitation of the Paralyzed (CRP), Savar, Dhaka, Bangladesh. This is a rehabilitation hospital for people with different disabilities. CRP was founded in 1979 in response to the desperate need for services for people with spinal injuries. Since then, CRP has developed into an internationally respected organization that focuses on a holistic approach to rehabilitation. One of its objectives is to provide treatment, rehabilitation and support services focusing on physical, emotional, social, psychological, and economic aspects. In Dhaka, CRP's headquarter Savar campus has a paediatric in-patient ward where 21 children with $\mathrm{CP}$ are admitted with their mothers for a 14 day intensive therapy service at a minimum cost. That is why this site was chosen primarily for convenience of data collection.

\section{Study Population}

Children with cerebral palsy and their caregiver who usually feed them at home.

Inclusion criteria:

- Children's age range-18 months to 36 months (corrected age) and have diagnosed cerebral palsy

- The caregiver present with the child is the main feeder of that child at home.

\section{Exclusion criteria:}

- Children aged less than 18 months or older than 36 months.

- The caregiver who was present with child at the hospital was not the main feeder of the child at home. 


\section{Sample Size}

Quantitative study: Sample size for the quantitative study was calculated by using the following formula:

$$
n=\frac{Z^{2} p(1-p)}{d^{2}}
$$

\begin{tabular}{ll|} 
Level of Confidence Measure (Z) & 1.96 \\
Margin of significance (p) & 0.50 \\
Marginal error (d) & 0.12
\end{tabular}

For this study, I used $95 \%$ confidence interval with proportion (p) of $50 \%$ as no study in Bangladesh had precise prevalence rate of responsive feeding. The larger study from where the quantitative data were extracted, that had around 66 videos of feeding session. So, to take those 66 videos as data of this study the marginal error was calculated as $12 \%$. So, according to the formula the required sample size were 66.

Qualitative study:

The main purpose of the qualitative study was to find out what caregivers think about the difficulties regarding feed the children with cerebral palsy, their view on their own characteristics of feeding style and the effect of their style on the child's nutrition. So, 2 focus group discussions (FGD) were conducted with the mothers. Each group had 6 mothers but one mother from second FGD left the discussion as her child was sick. So, finally it ended up with 5 mothers.

\section{Sampling techniques}

Quantitative: Though mother-child were available in the study place but considering the time limit for this thesis it was difficult to manage the time for direct observation of 66 feeding sessions. So, videos were extracted from a larger study where convenient sampling was used.

Qualitative: Convenient sampling was used to get the participants of FGD. 


\section{Data Collection Technique and Instruments Quantitative}

Observation of videotaped feeding episodes of 66 children for one main meal during the daytime revealed the quantitative data. These videotapes were the subset data of a larger Ph.D. study project named 'Queensland Cerebral Palsy Child: Growth, Nutrition and Physical Activity: Oropharyngeal Dysphagia in Bangladesh (OPD-BD study)' conducted by Benfer, 2015. These videotapes were led by the investigator and her research assistants of the large study. Investigator of this study took permission verbally from the researcher of Ph.D. (Benfer, KA) study to collect those videos.

To analyse the video a structured observational checklist was constructed to code the mother's and child's behaviour based on another study done in similar topic with typical developing children in Gazipur, Bangladesh. This checklist was pretested on observing first 7 videos because it was prepared for typical developing children who could be different from children with CP. Necessary changes had been made to code the behaviour appropriately for children with $\mathrm{CP}$ and their caregiver after pretesting.

This checklist included a coding system to category the behaviour of caregiver and child as active and/or responsive, distraction of caregiver and child, and caregiver's response to child's oropharyngeal dysphagia (OPD) behaviour. In addition to coding there were option for count number of total boluses and child's feeding position. The coding system was devised which consists of mainly active, responsive behaviour of caregiver, distraction, and response to child's OPD behaviour. Among these except distraction all other categories had a positive and negative classification where positive meaning behaviour that promoted feeding and negative meaning behaviour that was aversive, intrusive or interrupted feeding. All the categories were measured for both caregiver and child.

Active behaviour was defined if caregiver or child did anything towards direct feeding by him/her own. Moreover, active positive behaviour in case of caregiver was coded as caregiver encourages and keeps interested positive behaviour to feed the child whereas active negative behaviour was coded if caregiver's behaviour was aversive, intrusive attempts to direct feeding. In case of child active positive behaviour was coded as child's expression for want food and active negative behaviour was coded as child's expression for interrupted feeding. 
Responsive behaviour was defined synchronous behaviour of caregiver and child. On the caregiver's part responsive behaviour would be child driven. A positive responsive behaviour of caregiver was behaviour that promoted feeding in response to child's cue and a negative responsive behaviour of caregiver was behaviour that interrupted feeding in response to a cue. For the child a responsive behaviour was coded as child accepted food when it is offered and a responsive negative behaviour was if child refused food when it was offered.

Another option was included in the checklist when caregivers offer food without showing any behaviour and the caregiver was coded as neutral offer.

Distraction was coded separately for mother and child where the behaviour for both was distracted at any point of time during feeding session.

Response to OPD was only on mother's part and categorized as positive and negative. Positive response to OPD was coded as caregivers showed concerned and took any measurement to feel child comfort. Negative response to OPD was defined when caregivers did not show concern or the measurement, they took was uncomfortable for child. See annex for behavioural example of the code.

The codes were mutually exclusive for caregiver and child. Each meaningful unit of behaviour received a code for the category in the checklist. So, if a caregiver showed all four types of behaviour, she was coded in all four categories.

All the videos were observed and coded by the investigator of this study and randomly cross checked the coding system with the supervisor. Demographic characteristics of caregiver (age, education, family asset) and anthropometric measurement of child (length, weight) including child's age and gender was taken from the larger study database.

\section{Qualitative}

A pre-tested structured questionnaire was developed to conduct the FGD . The questionnaire was developed based on the video observation. Two research assistants were hired and trained how to conduct the FGD. FGD questionnaire was translated into Bangla by research assistants. At first permission from the paediatric department where the caregiver and child stayed was taken. From the register of the hospital children's age were collected and a list of children whose age is within 18 months and 36 months was made. Caregivers were informed about study and asked for voluntary participation in the study. Those who were 
agreed were included in FGD. They were allowed to bring the child with them because otherwise they would be worried for their child as there were not enough people to take care of the child meanwhile. Informed consent was taken with participant's sign prior to FGD. Ground rules were set and described by investigator. The duration of each FGD was approximately 1 hour. Questions were repeated and rephrased if caregivers did not answer the question appropriately or if they did not understand question. Investigator tried to use local word mostly for better comprehension of caregiver. Research assistants took notes during FGD, and investigator was the moderator. After finishing each FGD, within next day the transcript was made by research assistant.

\section{Data Analysis Technique Quantitative}

Microsoft Excel 2007 (Microsoft Corp.) was used for entering, cleaning, and editing the quantitative data primarily. Then all data was copied to stata 12.1 and the rest of the analysis was conducted in stata.

The entire behaviour category was grouped in two major ways. Firstly, all the behaviour for the major category was made as active positive which was written as act/pos, active negative as act/neg, responsive positive as res/pos and responsive negative as res/neg. The other way was to categorize the behaviour as only active behaviour which was summation of both positive and negative behaviour, responsive behaviour including both positive and negative behaviour, positive behaviour where both active positive and responsive positive were added up and finally only negative category which included both active negative and responsive negative behaviour. Then it was calculated as the proportion of total boluses offered to child and this proportion was taken for establishing correlation.

One of the main variables was refusal of food by child. During observing the video, it was noticed that children with $\mathrm{CP}$ were not physically able to refuse food as typical children. Typical children can sit within 18 months and can walk away or protest with hand if they want to refuse food. But the children with CP were seen in video as lying down mostly and caregivers hold their hand and head and then put food child's mouth where the child really had no opportunity refuse food even if they wanted to due to their physical difficulties. So, taking the original refusal of food when the child was successful to refuse the food would not provide a true picture of refusal rate for these children. Mostly caregivers used 
force feed when the child tried to refuse the food with a weak physical ability. That is why the number of forces feeding by caregiver was added up with the number of actual refusals by child to calculate the collapsed number of refusal and then it was calculated as proportion of total boluses. The total number of boluses varied very widely. So, considering only how many times the behaviour was practiced would not reflect the real scenario. As there was no common denominator, so the behaviour was calculated as proportion of total boluses.

The entire behavioural category was kept as continuous variable. The outcome variable for nutritional status of children was weight for age $\mathrm{z}$ score and to calculate this World Health Organization anthropometric software was used. It was kept as continuous variable and a category was made taking weight for age $\mathrm{z}$ score $<-2$ as median according to WHO. Children's age was calculated in months, and it was also considered as continuous variable.

Children's CP was classified according to Gross Motor Function Classification System (GMFCS). This classification system is based on child's self-initiated movement, particularly emphasize on the pattern of sitting and walking ability of the child (Palisano et al., 1997). It has 5 levels where level I represents mild gross motor difficulties and gradually the severity of CP increases with the GMFCS level up to level V. In this study the children with $\mathrm{CP}$ were classified in 3 categories as level I-II, level III, and level IV-V.

Univariate analysis was carried out using frequencies, percentage, mean and standard deviation.

For bivariate analysis correlation were used to determine the presence of statistically significant differences for categorical variables and continuous variable. All analysis was present through table, as there was mostly correlation.

\section{Qualitative}

For qualitative study, transcripts of focused group discussion were used for analysis. Coding of transcripts was done manually. After coding, the raw data were clustered and categorized and themes were identified from the raw data.

\section{Ethical Consideration}

Before conducting the study, an official approval for data collection was obtained from the research and evaluation department of the centre for the rehabilitation of 
the paralyzed (CRP). The ethical clearance for the study was obtained from the Ethical Committee of the James P. Grant School of Public Health, BRAC University. Respondents of focused group discussion were fully informed about the study and had the rights for withdrawing themselves from the study at any time. Informed written consent was taken prior to focus group discussion from the caregiver of the child. Confidentiality of information was ensured at all levels and were not disclosed without their consent. Consent of the participants had already been taken prior to making the video as a part of the Ph.D. study project named 'Queensland Cerebral Palsy Child: Growth, Nutrition and Physical Activity: Oropharyngeal Dysphagia in Bangladesh (OPD-BD study)'.

\section{Findings}

This section presents an overview of sample characteristics for both child and caregiver through descriptive statistics and relationship between weight for age, proportion of refusal and caregiver's feeding pattern through correlation. Child's age and feeding duration was also used in correlation as potential confounder. Moreover, qualitative analysis presents theme and caregiver's quotation accordingly.

\section{Quantitative Findings}

Table 1: Characteristics of child participants

\begin{tabular}{|l|l|l|}
\hline & Mean (SD) & n $(\%)$ \\
\hline $\begin{array}{l}\text { Child's gender } \\
\text { Male } \\
\text { Female }\end{array}$ & na & $\begin{array}{l}43(65.15) \\
23(34.85)\end{array}$ \\
\hline Child's age & $26.15(6.40)$ & \\
\hline $\begin{array}{l}\text { GMFCS } \\
\text { Level I-II }\end{array}$ & na & $13(19.70)$ \\
Level III & & $22(33.33)$ \\
Level IV-V & & $31(46.97)$ \\
\hline
\end{tabular}




\begin{tabular}{|l|l|l|}
\hline $\begin{array}{l}\text { Weight for age } \\
\text { Low weight for age }(Z<-2)\end{array}$ & $-2.08(1.70)$ & $41(62.12)$ \\
$\begin{array}{l}\text { Normal weight for age } \\
(Z>=-2)\end{array}$ & & $25(37.88)$ \\
\hline Weight for height & $-1.58(1.41)$ & \\
\hline
\end{tabular}

Key: GMFCS Gross Motor Function Classification System; na not applicable; SD Standard Deviation; z score

A total of 66 caregiver-child participated in this study, with the child characteristics presented in Table 1 . Among them $65 \%$ were male and $35 \%$ were female children who reflect the typical gender ratio expected in cerebral palsy (Johnston \& Hagberg, 2007). Children's age was measured in months. The mean age of children was 26.15 months. The type of $\mathrm{CP}$ was categorized according to GMFCS level. 20\% of children had GMFCS level I-II, 33\% of children had level III and $47 \%$ of children had level IV-V CP. The mean weight for age z score was 1.58 , where the minimum $\mathrm{z}$ score was -4.89 which is severe under nutrition and maximum is also 4.04 which is over nutrition. Considering the $\mathrm{z}$ score -2.00 as median to categorize it into two group, it was found that $62 \%$ of children had low weight for age and the rest $38 \%$ of children had normal weight for their age. For further analysis this category has been used. Mean of weight for height was 1.58 in children

Table 2: Socio demographic characteristics of caregiver

\begin{tabular}{|l|l|l|}
\hline Variable (N=66) & Mean (SD) & N $(\%)$ \\
\hline $\begin{array}{l}\text { Relationship to child } \\
\text { Mother }\end{array}$ & na & $64(96.97)$ \\
Grandmother & & $2(3.03)$ \\
\hline Age & $24.80(5.72)$ & \\
\hline Highest education level & & \\
No school & & $8(12.12)$ \\
Up to SSC & & $46(69.70)$ \\
HSC & & $6(9.09)$ \\
Tertiary & & $6(9.09)$ \\
\hline
\end{tabular}




\begin{tabular}{|l|l|}
\hline Occupation & \\
Housewife & $59(89.39)$ \\
Employed & $7(10.61)$ \\
\hline Economic level* & \\
Well off & $19(30.16)$ \\
Moderately well off & $22(34.92)$ \\
Not so well off & $13(20.63)$ \\
Poor & $4(6.35)$ \\
Very poor & $5(7.94)$ \\
\hline
\end{tabular}

*Economic level based on Poverty Measurement Tool (Bhuiyan et al, 2007)

Table 2 presents socio-demographic characteristics of caregiver. $97 \%$ of the caregiver was mother while only $3 \%$ of caregiver was grandmother of the child. Mean age of caregiver was 24.8 years and the range was 18 years to 45 years. Looking into caregiver education category, $12 \%$ of caregiver had no schooling whereas $70 \%$ of them went to school, $9 \%$ had education up to HSC level and another $9 \%$ of them had tertiary education. $89 \%$ of caregiver had no employment while other $11 \%$ were employed. Family assets were measured by poverty measurement tool. $30 \%$ of the caregivers were categorized as well-off family, $35 \%$ were moderately well off, $21 \%$ were not so well off, $6 \%$ were poor and $8 \%$ of caregivers were very poor.

Table 3: Patterns of caregiver/child feeding styles in young children with $\mathbf{C P}$ Mean, range and SD showing caregiver's feeding style for percentage of boluses

\begin{tabular}{|c|c|c|c|c|c|c|c|c|}
\hline \multirow{3}{*}{$\begin{array}{l}\text { Behavioural } \\
\text { categories }\end{array}$} & \multicolumn{4}{|l|}{ Mother } & \multicolumn{4}{|l|}{ Child } \\
\hline & \multicolumn{2}{|l|}{ Descriptive } & \multicolumn{2}{|c|}{ Frequency* } & \multicolumn{2}{|l|}{ Descriptive } & \multicolumn{2}{|c|}{ Frequency } \\
\hline & $\begin{array}{l}\text { Mean } \\
\text { proportion } \\
\text { of boluses } \\
\text { (SD) }\end{array}$ & Range & $\mathrm{N}$ & $\%$ & $\begin{array}{l}\text { Mean } \\
\text { proportion } \\
\text { of boluses } \\
\text { (SD) }\end{array}$ & Range & $\mathrm{N}$ & $\%$ \\
\hline
\end{tabular}




\begin{tabular}{|c|c|c|c|c|c|c|c|c|}
\hline $\begin{array}{l}\text { Active } \\
\text { Positive } \\
\text { Negative }\end{array}$ & $\begin{array}{l}39.01 \\
(22.12) \\
24.37 \\
(20.73) \\
14.61 \\
(17.44)\end{array}$ & $\begin{array}{l}0-100 \\
0-100 \\
0- \\
72.41\end{array}$ & $\begin{array}{l}51 \\
31\end{array}$ & $\begin{array}{l}72.27 \\
46.97\end{array}$ & $\begin{array}{l}8.37 \\
(13.14) \\
9.83 \\
(15.24)\end{array}$ & $\begin{array}{l}0- \\
77.78 \\
0- \\
71.43\end{array}$ & $\begin{array}{l}23 \\
27\end{array}$ & $\begin{array}{l}34.85 \\
40.91\end{array}$ \\
\hline $\begin{array}{c}\text { Responsive } \\
\text { Positive } \\
\text { Negative }\end{array}$ & $\begin{array}{l}25.37 \\
(17.39) \\
17.63 \\
(13.95) \\
7.73 \\
(11.20)\end{array}$ & $\begin{array}{l}0- \\
70.00 \\
0- \\
57.40 \\
0- \\
55.26\end{array}$ & $\begin{array}{l}46 \\
28\end{array}$ & $\begin{array}{l}69.70 \\
42.42\end{array}$ & $\begin{array}{l}88.11 \\
(16.17) \\
13.29 \\
(17.84)\end{array}$ & $\begin{array}{l}11.76- \\
100 \\
0- \\
88.24\end{array}$ & $\begin{array}{l}64 \\
44\end{array}$ & $\begin{array}{l}96.97 \\
66.67\end{array}$ \\
\hline Distraction & $\begin{array}{l}4.69 \\
(9.29)\end{array}$ & $\begin{array}{l}0- \\
52.17\end{array}$ & 15 & 22.73 & $\begin{array}{l}2.53 \\
(4.63)\end{array}$ & $0-25$ & 9 & 13.64 \\
\hline $\begin{array}{l}\text { Neutral } \\
\text { offer }\end{array}$ & $\begin{array}{l}39.62 \\
(25.31)\end{array}$ & $\begin{array}{l}0- \\
90.91\end{array}$ & 56 & 84.85 & NA & NA & NA & NA \\
\hline$\%$ of refusal & & & & & $\begin{array}{l}21.42 \\
(23.48)\end{array}$ & & & \\
\hline
\end{tabular}

Table 3 includes data from $n=63$, as 3 mother-child dyads were excluded who had bottle feeding; *Frequency of feeders/ children classified as this feeding style, based on presence of $2+$ of this behaviour during mealtime (Moore et al, 2005).

Mothers showed on average active positive behaviour $24 \%$ of total boluses, active negative behaviour $15 \%$ of total boluses, responsive positive behaviour $18 \%$ of total boluses and responsive negative behaviour $8 \%$ of total boluses in this study. In case of children, the mean of showing active positive behaviour was $8 \%$, active negative behaviour was $10 \%$, responsive positive behaviour was $88 \%$ and responsive negative behaviour was $13 \%$. Caregivers neutrally offered food on average $40 \%$ of boluses. Proportion of food refusal out of total bolus was $21 \%$.

Caregivers were distracted during feeding session on average 5\% of boluses and children were distracted $3 \%$ of boluses. 
Table 4: Relationship between caregiver's and child's feeding styles and child's age

\begin{tabular}{|l|l|l|l|l|}
\hline \multirow{2}{*}{$\begin{array}{l}\text { Child's } \\
\text { feeding } \\
\text { style }\end{array}$} & \multicolumn{4}{|l|}{ Correlation to caregiver's feeding style (Pearson's R) } \\
\cline { 2 - 5 } & $\begin{array}{l}\text { Active } \\
\text { positive }\end{array}$ & $\begin{array}{l}\text { Active } \\
\text { negative }\end{array}$ & $\begin{array}{l}\text { Responsive } \\
\text { positive }\end{array}$ & $\begin{array}{l}\text { Responsive } \\
\text { negative }\end{array}$ \\
\hline $\begin{array}{l}\text { Active } \\
\text { positive }\end{array}$ & $0.07(0.55)$ & $-0.24(0.04)$ & $0.43(<0.01)$ & $-0.06(0.58)$ \\
\hline $\begin{array}{l}\text { Active } \\
\text { negative }\end{array}$ & $0.36(<0.01)$ & $0.15(0.22)$ & $0.20(0.10)$ & $-0.09(0.47)$ \\
\hline $\begin{array}{l}\text { Responsive } \\
\text { positive }\end{array}$ & $-0.33(<0.01)$ & $0.06(0.62)$ & $-0.12(0.32)$ & $0.17(0.16)$ \\
\hline $\begin{array}{l}\text { Responsive } \\
\text { negative }\end{array}$ & $0.25(0.04)$ & $0.03(0.78)$ & $0.07(0.57)$ & $-0.15(0.22)$ \\
\hline $\begin{array}{l}\text { Child's age } \\
\text { in months }\end{array}$ & $0.18(0.14)$ & $-0.22(0.07)$ & $0.11(0.35)$ & $-0.009(0.94)$ \\
\hline
\end{tabular}

$\mathrm{P}$ values are in parenthesis.

The correlation between caregiver's feeding styles and children feeding styles alongside with child's age is shown in table 4. Caregiver's active positive style positively affected child's active positive, active negative and responsive negative behaviour whereas it negatively affected child's responsive positive behaviour. Among other style, caregiver's active negative behaviour negatively related with child's active positive behaviour and responsive positive caregiver positively related with active positive child.

The covariate of age is not affecting the model.

Table 5: Relationship between caregiver's feeding style and proportion of child bolus refusals

\begin{tabular}{|l|l|l|}
\hline Behavioural codes & \multicolumn{2}{|l|}{$\begin{array}{l}\text { Correlation to proportion of child refusals } \\
\text { Pearson's R (p value) }\end{array}$} \\
\hline Active positive & $0.10 \quad(0.42)$ & \\
\hline Active negative & $0.45 \quad(<0.01)$ & \\
\hline
\end{tabular}




\begin{tabular}{|l|l|l|}
\hline Responsive positive & $-0.03 \quad(0.77)$ & \\
\hline Responsive negative & $-0.15 \quad(0.13)$ & \\
\hline Neutral offer & $-0.19 \quad(<0.01)$ & \\
\hline Active & $0.45 \quad(0.31)$ & \\
\hline Responsive & $-0.12 \quad(0.31)$ & \\
\hline Positive & $0.05 \quad(0.65)$ & \\
\hline Negative & $0.28 \quad(0.02)$ & \\
\hline
\end{tabular}

The relationship between the caregiver's feeding style and the proportion of child boluses refusal

is shown in table 5. Correlation between the outcome variable proportion of refusal and exposure variable caregiver's behavioural codes showed active and negative caregiver positively affected bolus refusal of the child whereas other behaviours were negatively associated.

Table 6: Correlation between duration of feeding and the caregiver's behaviour

\begin{tabular}{|c|c|c|}
\hline $\begin{array}{l}\text { Behavioural } \\
\text { (proportion) }\end{array}$ & $\begin{array}{l}\text { Time } \\
\text { Pearso }\end{array}$ & $\begin{array}{l}\text { eding } \\
\mathrm{R} \text { (P value) }\end{array}$ \\
\hline Active positive & 0.05 & $(0.68)$ \\
\hline Active negative & -0.28 & $(0.02)$ \\
\hline Responsive positive & -0.06 & $(0.62)$ \\
\hline Responsive negative & 0.36 & $(<0.01)$ \\
\hline Active & -0.17 & $(0.16)$ \\
\hline Responsive & 0.18 & $(0.15)$ \\
\hline Positive & 0.01 & $(0.95)$ \\
\hline Negative & -0.04 & $(0.74)$ \\
\hline Neutral offer & -0.09 & $(0.44)$ \\
\hline
\end{tabular}


The correlation between caregiver feeding style and duration of mealtime is shown in table 6 which showed a very weak positive relation of active positive behaviour with duration of feeding. A significant negative relation with active negative behaviour and positive relation with responsive negative behaviour had been found whereas responsive positive behaviour had very weak negative relation with duration of feeding.

In case of active behaviour, a weak negative relation was found. Responsive behaviour group and positive behaviour group had positive relation; and negative behaviour group and neutral offer had negative relation with the duration of feeding.

Table 7: Correlation between weight for age $\mathrm{z}$ score (WAZ) and caregiver's behaviour

\begin{tabular}{|l|l|l|}
\hline $\begin{array}{l}\text { Behavioural } \\
\text { (proportion) }\end{array}$ & \multicolumn{2}{|l|}{$\begin{array}{l}\text { Codes } \\
\text { Pearson's R (P value) }\end{array}$} \\
\hline Active positive & 0.02 & $(0.83)$ \\
\hline Active negative & -0.12 & $(0.34)$ \\
\hline Responsive positive & -0.11 & $(0.35)$ \\
\hline Responsive negative & 0.11 & $(0.35)$ \\
\hline Active & -0.07 & $(0.57)$ \\
\hline Responsive & -0.01 & $(0.88)$ \\
\hline Positive & -0.03 & $(0.75)$ \\
\hline Negative & -0.03 & $(0.78)$ \\
\hline Neutral offer & 0.05 & $(0.66)$ \\
\hline
\end{tabular}

Table 7 showed the relationship between outcome variable weight for age $\mathrm{z}$ score (WAZ) of children and exposure variable caregiver's behaviour. There was no significant relationship between caregiver's feeding style and child's WAZ with active positive behaviour and responsive negative behaviour had a weak positive relation with WAZ whereas active negative and responsive positive behaviour had a weak negative relationship. 


\section{Qualitative findings}

To understand caregivers' perception about how their feeding practices affect their children, particularly nutrition, and parents challenges, 2 FGD were conducted, containing 6 caregivers in each group whose children's were within 18-36 months. One caregiver left second FGD because her child was sick. Caregivers were chosen from the same hospital (CRP) where the feeding observation was done. The aim of the FGD was to understand caregiver's perception about how their feeding practices affect their children, particularly nutrition, and what challenges they faced while feed the child.

\section{Feeding pattern}

All the caregivers answered to question about their feeding pattern mentioning the position, types of food and equipment.

\section{Feeding routine}

Most of the caregivers said that they feed their child at fixed time. Only 1 caregiver said she gave food when child showed any sigh of hunger. In response to the question why they prefer feeding at fixed time, the common reasons were they had other work to do beside feed this child, they had more children to take care of and this child had been used to take food at this time.

One caregiver said, "What do you mean by why I do, don't I need to do work? It is necessary to find out a specific time to feed." FGD 2, R3

\section{Feeding position}

Over half of the caregivers reported that they feed child in lying or half lying position. Others feed their child in sitting position because their children can sit. They also mentioned that lying or half lying position is easier to control the child.

One caregiver said, "my son does not want to eat.....I feed him on my laps holding very tightly." FGD 2, R2

Another caregiver reported, "I feed my child in lying position on my lap. And if she eats any solid food, she eats herself." FGD 1, R5 


\section{Action upon refusal of food by child}

Very few caregivers agreed that they use force feeding if child refuse food. Most of caregivers said that they wait, stop feeding and tried later if necessary. Although some of these caregivers described force feeding in response to other questions.

One of the mothers told, "my child will not eat by his own wish. Need force feed, he needs force because he will not eat otherwise" FGD 2, R2

Another mother said, "I show her the nature. When she doesn't want to eat, I do not force her to eat." FGD 1, R3

\section{Verbalization used during feeding}

Few caregivers said that they do not use verbalization with child whereas others reported they use verbalization while feeding. The types of verbalizations they used are reciting poem, verbal command to child to eat or stop crying, talks about something other than food.

One caregiver said, "I speak, what he is eating, also tell that we will go out, eat quickly then will go out, your father is coming, don't you want to be on my lap? Like this, need to say lie.” FGD1, R5

another respondent said, "I talk; not very much. He eats when he wants to eat. If I talk, he may not eat. I talk very limited at that time." FGD 1, R2

Duration of the verbalization varied among mothers, half of them said for whole feeding session and half of them said that they would start talking at the beginning, but once child start eating, they stopped.

One caregiver said, "I don't talk for the whole time. When she holds her feeder then I talk and then I stop talking when she starts eating." FGD 2, R5

\section{Challenges during feed the child}

A list of challenges had been identified by caregiver those they faced during feed their child. Those were drooling, spit out, vomit, chewing problem, inability to eat solid food, not eager to eat food, cough during feeding, takes long time to feed and difficult to manage the child. 
One caregiver said that "during feeding my baby.... if I try to feed him, he doesn't want to eat, he wants to feed himself. If I feed him, sometimes he eats, sometimes doesn't....needs many toys during feeding. " FGD 1, R2

Another mother said, "Drools when I feed, and also drool when he chews and swallow. ” FGD 2, R1

\section{Positive and negative effects of current feeding style}

Caregiver did not really identify a range of positive or negative side of their practiced feeding behaviour. They identified only force feeding as a negative attitude for children's learning and self-feeding by children as a positive side of feeding session.

One caregiver reported, "The good side is if the child eats then his tummy gets full.... and the negative side is when I feed him, he can't learn anything." FGD 2, R1

\section{Difficulties to change current practice}

The common difficulties, identified by most caregivers, to change the current practiced are child's inability to sit, children did not develop self-feeding, difficulty to manage the child due to children's physical difficulties and mothers were habituated now with current practice. They also mentioned to feed the child properly caregivers need time which is difficult to manage doing other work.

One caregiver said, "if I feed him in sitting position, he moves a lot, can't feed him " FGD 1, R1

\section{DISCUSSION}

The style of responsive feeding has received growing interest in the field of nutrition. Several studies are being conducted to elaborate on the framework of responsive feeding practices and implementation of related interventions for clinicians working in the area of malnutrition (Moore et al., 2005). The findings of this study will contribute to expand the focus of responsive feeding from typically developing children to children with disabilities. The findings are discussed here according to the objectives of this study. 


\section{Pattern of Caregiver's and child's feeding styles}

Caregivers and children with $\mathrm{CP}$ in this study demonstrated a range of different behaviours. Overall, more positive behaviours were observed than negative behaviours. In addition to positive/negative style frequency of caregiver/children based on presence of $2+$ behaviours (Moore et al. 2005) showed more caregivers used active style than responsive style (see table 3). Finding from similar type of study in Bangladesh with typically developing children showed similar pattern of feeding style (Moore et al. 2005) but comparing percentage of caregiver used the style were higher in this study. So, caregivers of children with CP were more frequent in using all the feeding styles than the caregiver of typically developing children. Possible causes of caregiver of children with CP being more frequent in using the behaviour can be these children take very small number of boluses at a time and it takes time to finish the food. Moreover, due to physical difficulties of these children, they are hold by caregiver in lap or arm. So, like typical children they cannot go away from caregivers. That is why caregiver gets more turn and time to use those behaviours with children with $\mathrm{CP}$.

In addition to mean, if we look at how proportionally caregivers used these behaviours out of total number of boluses, on average caregivers used active behaviour only $39 \%$ of the time whereas responsive behaviour was used $25 \%$ of the time. A study in Vietnam done in typically developed children showed that caregivers verbalized during only $30 \%$ of time child accepted the offered food, and only half of these verbalizations were responsive positive in tone or words (Ha et al. 2002) which is almost similar to this study (18\%). So, caregivers of children with CP mostly used active behaviour rather than responsive behaviour and proportion of using active negative behaviour is almost similar to using responsive positive behaviour. In case of children with $\mathrm{CP}$ caregivers needs to be more involved than the caregiver of typically developing children as children with CP needs more assistance during feeding (Farluga, 2013). Caregivers also reported during FGD that they tried to feed children mostly using talking and distraction technique. They start it at the beginning of feeding but usually do not continue for the whole time and when children showed negative behaviour, they usually tried to finish the food anyhow which cannot be responsive. 


\section{Association between caregivers and child's behaviour}

Children's feeding styles were mostly related with caregiver's active feeding styles. Among other styles significant relationship was found between caregiver used active negative and responsive positive and active positive child. Active children were positively related with positive caregiver. It might be due to positive caregiver actively promoted feeding (i.e., talks about food, encourage the child), interpreted child feeding cues or responded to child needs, so the children might be encouraged to use feeding cues which makes them active. However, the children's development of communication also may affect the child's ability to be active which should be considered in future studies. In 2005 Moore et al. also found association between mother's behaviour and child's active and responsive behaviour, but they failed to establish any specific causalities except saying it as avenues of mutual influence.

Caregivers also reported that if children ate properly then they did not need to use force feed and negative verbalization. They also mentioned child's inability to request for food and self-feeding as difficulties in feeding practices.

"If he could eat then he would eat through his hand. According to his age, perhaps he can't eat by himself and thats why needs to push." FGD1, R2.

So children's behaviour is associated with caregiver's behaviour but the magnitude of this association was not identifiable in this study.

\section{Effect of feeding practices upon children's food refusal}

Caregiver's active feeding behaviours were found significantly positively correlated with child's food refusal in this study. When active behaviours were divided into positive and negative, the association with food refusal was maintained only for active negative behaviours (i.e., force feeding, threats child, and pushes food into mouth before finishing the previous mouthful). So, when caregiver uses active negative behaviour child refuses more food. There was a negative trend (i.e., less refusals) observed when responsive feeding approaches were used by mother, but that this was not significant. The similar finding was found in a study among 12-17 months old typically developing Vietnamese children that when caregivers used positive comments then child accepted food 2.4 times higher compare with when no comments were provided (Dearden et al., 2009). A randomized control trial among typically developing children in 
Bangladesh found no significant difference of food refusal after providing educational intervention to the mother (Aboud, Shafique \& Akhter, 2009). Another study found mother's verbal responsiveness higher in intervention group that also had significantly lower refusal immediately after intervention, but which was not same after 5 months follow up (Aboud et al., 2009). But both studies concluded that the type of verbalization plays important role on child's acceptance/refusal of food but need to identify the effect of other behaviour of caregiver. In this study we found that with increasing active negative behaviour the refusal of food increases.

Caregivers said that if the child showed interest to eat, they would not use force feed and their stress for feeding the child could be less. Unwillingness to take food, inability to self-feeding and attempts to refusal makes them to go hard line as force-feeding.

"If he/she eats willingly then forcing is not necesary. As he/she doesn't eat willingly thats why I feel irritated...that how I can feed?" FGD1, R5

\section{Relation between feeding behaviour, child's age and feeding duration}

With increasing children's age in month caregivers uses more active positive and responsive positive behaviour and decreases negative behaviour for both categories. Findings from few other studies on typically developing children showed mothers used active positive behaviour and encourage self-feeding more with older age group who were older than 18 months olds (Bhandari et al. 2004 $\&$ Moore et al. 2005) but were not responsive with older age group (Moore et al., 2005). Result can differ as the participants are different in their physical ability. In case of children with $\mathrm{CP}$ older aged children could be more capable with their disabilities and become familiar and habituated with the feeding practices by caregiver. As these children have developmental delay (Ferluga et al, 2013), so they may develop expression of requesting or refusing food far later than their chronological age. Caregiver's responsive behaviour depends on child's cue because it is considered how a mother responds to child feeding cues. Unless these children develop any expression using as feeding cues, caregivers will have very little opportunity to use responsive behaviour.

Caregivers who used negative feeding behaviours were significantly associated with different mealtime duration; however active negative associated with decreased duration whereas active positive was associated with an increased 
duration. It might be the reason that caregivers used active positive behaviour spends more time during feeding to keep the child interested or encouraged. A systematic review of studies on feeding practices with $\mathrm{CP}$ mentioned children with $\mathrm{CP}$ might require considerable time to feed and due to this time duration caregivers might have stress and fatigue which in turn affect the feeding process (Ferluga et al., 2013).

This study showed with increased duration responsive negative increased. When it takes long time to feed, caregivers may want to finish the food quickly and they ignore child's cue. But it could be occurred for active negative behaviour too which is surprisingly decreased with the increasing time.

Caregivers also mentioned that they tried to talk with child during feeding, but they could not continue for the whole time. They started at the beginning and when child started eating, they gradually stopped. So, with the increasing time duration for feeding caregiver's used less talking which is assumed as active behaviour in this study.

\section{Responsive feeding practices and children's nutritional status}

In this study, over half of children with $\mathrm{CP}$ were underweight for their age, with weight for age $\mathrm{z}$ scores ranging from -4.89 to 4.04. A study conducted in Brazil on food pattern and nutritional status of children with CP found $40 \%$ of children had weight for age $z<-2$, study in Bangladesh on caregiver training to improve feeding of children with $\mathrm{CP}$ found baseline mean weight for age $\mathrm{z}$ score -4.83 for 37 children ages between 1-11 years old and a systematic review on effectiveness of intervention for feeding difficulties for children with $\mathrm{CP}$ found baseline weight for $\mathrm{z}$ score ranged from -3.56 to -0.39 in nine case series worldwide. Weight for age did not differ based on gender of child and age in this study.

Weight for age z scores did not appear to be strongly related to the caregiver's feeding patterns, with all analysis non-significant. The study by Adams et al. (2012) in Bangladesh with children with CP focused on caregiver's training to improve feeding practices found improvement in mean weight for age $\mathrm{z}$ score after intervention though their intervention employed a range of low-tech approaches, including the promotion of responsive feeding behaviour. Other intervention studies on typically developing children when using education to increase responsiveness (Aboud et al, 2009) and to promote complementary feeding (Bhandari et al, 2004). The change in weight for age could be different 
for children with $\mathrm{CP}$ compared to typically developing children as children with $\mathrm{CP}$ are more underweight than their typical counterparts (Yousafzai, 2003 \& Grammatikopoulou, 2009). Children with CP have complex oral sensorimotor feeding impairments, in which case responsive feeding alone is insufficient to make a change for their nutrition. This issue needs to be addressed in further study.

Caregivers from the FGD also did not mention anything about their children's nutritional status when they were asked to find out any good or bad consequences of their current feeding practices.

\section{Limitations of the Study}

- As a cross-sectional study it is difficult to indicate the direction of relation between the variables. A large sample size was also needed to see the see the significant relation between variables.

- To get an appropriate sample size calculation prevalence rate among the study population was needed but no literature was found among study population. However, prevalence among typically children also varied among literature due to difference in defining responsive behaviour.

- Sampling method was convenience and sample was taken from hospital. So, the behaviour caregiver showed in this study could differ from the home settings. That's why the findings may not be generalized for the entire population.

- Though in different literature it was recommended to observe the caregiver's behaviour through video so that no behaviour can be missed out, but in this study sometimes caregiver was distracted for video.

- Due to coding system caregivers fall into more than one category which was difficult to analysis for multivariate analysis. Moreover, due to difference in coding caregiver's behaviour and making the group it was difficult to compare the result within literature.

\section{Conclusion}

In developing countries under nutrition is a one of major concerns for children's health status which is even more crucial among children with disabilities. In low resource country like Bangladesh where even the approximate number of 
children with $\mathrm{CP}$ has not been calculated, these children are deprived from the comprehensive health care needed for them. The consequence of CP makes them marginal group who needs more attention to their health and nutrition. Feeding difficulties beside poor food intake makes them vulnerable for under nutrition. Caregivers also play a great role among children with $\mathrm{CP}$ due to their dependency on caregivers for their feeding.

This study was an attempt to find out the caregiver's role during feeding upon children's nutrition and food refusal. Despite of the limitation, this study finding reflects that there is relation between caregiver's behaviour and child's food refusal. Caregiver's behaviour also has effect on and influenced by child's behaviour. The magnitude of this relationship should be more explored. However, it was not clear whether it influences children's weight or not. Moreover, the cause of food refusal whether it is due to caregiver's behaviour or their feeding difficulties can be crucial for better understanding the relation between caregiver's behaviour, food refusal and children's nutritional status.

In developing countries interventions for children with $\mathrm{CP}$ to improve their nutrition are mostly institution based and focus on children's position, food modification and improve oral motor skill. Currently in developing countries educational intervention which focuses caregivers' involvement is becoming a popular method to improve children's nutrition status in community. Though these interventions are mostly occurring in a small-scale project for typically developing children, it can be also implied for children with $\mathrm{CP}$ where feeding difficulties are most common as well as caregivers are important for their nutrition.

\section{Recommendation}

- There is a great need of study focused on nutrition of children with disabilities in a large scale.

- Further research can be focused on the direction of the relationship between caregiver's behaviour and food refusal.

- Longitudinal study and randomized control trial with interventions can provide interesting result.

- Finally, policy makers in health sector should be more concerned to improve the nutrition of children with disabilities. 


\section{References}

Aboud, F. E., Shafique, S. \& Akhter, S. (2009). A Responsive Feeding Intervention Increases Children's Self-Feeding and Maternal Responsive ness but Not Weight Gain, Journal Nutrition, 109, 9, 1738-43. Retrieved on June 8, 2013, from http://jn.nutrition.org/ content/139/9/1738.full

Adams, M. S., Khan, N. Z., Begum, S. A., Wirz, S. L., Hesketh, T., \& Pring, T. R. (2012). Feeding difficulties in children with cerebral palsy: low-cost caregiver training in Dhaka, Bangladesh. Child: care, health and development, 38(6), 878-888. Retrieved on January 8, 2014 from http://www.ncbi.nlm.nih.gov/pubmed/22082112

Akhtaruzzaman, M, Khan, N. I., \& Islam, S.N. (2013).Nutrition, health and Demographic Survey of Bangladesh, Institute of Nutrition and Food Science University of Dhaka, 21. Retrieved on July 2, 2013 from http://www.du.ac.bd/DownLoads/qlink/nhadsb.pdf

Benfer, KA. (2015). Oropharyngeal dysphagia in preschool children with cerebral palsy: relationship to gross motor function, dietary intake, and nutritional status [Doctoral thesis, The University of Queensland]. Retrieved on May 23, 2013 from https://espace.library.uq.edu.au/ data/UQ_363803/s33636386_phd_submission.pdf?Expires= $1629249794 \&$ KeyPairId=APKAJKNBJ4MJBJNC6NLQ\&Signature=e9Z 1PqzEkcXa7Vdfqy z5agcEm vvEeqQnszVVRHZdb1sLou2upiJ01m qKRcLBy1sO HJ2D2BWqvFYhlEZdLIHv ex2tPUIrJofSvHQM72M0Jcx2Tc10WajhmCEZ12OqIphZjaw5IvJPXiKIFQjrlUt5VzH3RXAc NbLjF3rpWfnWO0KJtcafK6dzHDKFLsuEwId7CNJ3v0wVMKFXtSxP1MmdoQPVtCaAZs0 al-vAhPb2MZhQQyiG8VYm 6qeCmRithWQKnLehvWU8yuGHNqtFHfsGjsYF1bpkLWHdp RoXDKxDSGy0YPYmi3CIwQoIb5 db5efcpSn9ssR6Ei9svA_

Bentley, M.E., Wasser, H.M., \& Creed-Kanashiro, H.M. (2011).Responsive Feeding and Child Under nutrition in Low- and Middle-Income Countries, Journal of Nutrition, 141, 3, 502-7, doi: 10.3945/jn.110.130005. Retrieved on June 27, 2013 from http://jn.nutrition.org/ content/141/3/ 502.abstract

Bhandari, N., Mazumder, S., Bahl, R., Martines, J., Black, R. E., \& Bhan, M. K. (2004). An educational intervention to promote appropriate complementary feeding practices and physical growth in infants and young children in rural Haryana, India. The Journal of nutrition, 134(9), 2342-2348. Retrieved on January 8, 2014 from http://nutrition.highwire.org/content/134/9/ 2342.short

Black, M. M., \& Aboud, F. E. (2011). Responsive feeding is embedded in a theoretical framework of responsive parenting, Journal Nutrition, 141, 3, 490-94, doi: 10.3945/jn.110.129973. Retrieved on June 8' 2013from http://www.ncbi.nlm.nih.gov/pmc/articles/PMC3040905/

Dearden, K. A., Hilton, S., Bentley, M. E., Caulfield, L. E., Wilde, C., Ha, P. B., \& Marsh, D. (2009). Caregiver verbal encouragement increases food acceptance among Vietnamese toddlers. The Journal of nutrition, 139(7), 1387-1392. Retrieved on January 8, 2014 from http://jn.nutrition.org/content/139/7/1387.short

Ferluga, E. D., Archer, K. R., Sathe, N. A., Krishnaswami, S., Klint, A., Lindegren, M. L., \& McPheeters, M. L. (2013). Interventions for Feeding and Nutrition in Cerebral Palsy. Retrieved on January 8, 2014 from http://www.effectivehealthcare.ahrq.gov/ehc/ products/436/1426/ Cerebral-Palsy-Feeding-Nutrition-130318.pdf

Fung, E. B., Samson-Fang, L., Stallings, V. A., Conaway, M., Liptak, G., Henderson, R. C., ... \& Stevenson, R. D. (2002). Feeding dysfunction is associated with poor growth and health status in children with cerebral palsy. Journal of the American Dietetic Association, 102(3), 361-373. Retrieved on August 4, 2013 from http://www.sciencedirect.com/science/article/pii/ S0002822302900842 
Ha, P.B., Bentley, M.E., Pachon, H., Sripaipan, T., Caulfield, L.E., Marsh, D.R., \& Schroedr, D.G. (2002). Caregiver styles of feeding and child acceptance of food in rural Vietnam, Food and Nutrition Bulletin, 23, 4. Retrieved on June 11, 2013 from http://www.positivedeviance.org/ pdf/fnb23_92-98.pdf

ICDDR,B. (2011). Health and Science Bulletin 9,1. Retrieved on June 10, 2013 from http://www.icddrb.org/what-we-do/publications/cat_view/52-publications/10042-icddrbperiodicals/10048-health-and-science-bulletin-bangla-and-english/10065-vol-9-no-1-english$\underline{2011}$

Horta, B. L., Bahl, R., Martines, J. C., \& Victora, C. G. (2007). Evidence on the long-term effects of breastfeeding: systematic review and meta-analyses. On June 10, 2013 WHO 2007.

Hou M, Fu P, Zhao JH, Lan K, \& Zhang H. (2004). Oral motor dysfunction, feeding problems and nutritional status in children with cerebral palsy, Chinese journal of Pediatrics,42(10), 765-8 retrieved on July 17, 2013 from http://nsinf.publisher.ingentaconnect.com/content/nsinf/ fnb/2002/00000023/A00204s2/art00013

Johnston, M. V., \& Hagberg, H. (2007). Sex and the pathogenesis of cerebral palsy. Developmental Medicine \& Child Neurology, 49(1), 74-78.Retrieved on January 8, 2014 from http://onlinelibrary.wiley.com/doi/10.1017/S0012162207000199.x/full.

Kumar, D., Goyel, N. K., Mittal, P. C., \& Mishra, P. (2006). Influence of Infant-Feeding Practices on Nutritional Status of Under 5 Children, Indian Journal Paediatrics, 73, 417-21.

Moore, A. C., Akhter, S., \& Aboudc, F. E. (2005), Responsive complementary feeding in rural Bangladesh, Social Science \& Medicine, 62, 8, 1917-1930 retrieved from personal contact

Muiruri, J., Hulcome, P., Schumacher, B., Parveen, M., Bilkes, F., \& Mehjabeen, S. S. (2012). Bangladesh Nutrition Strategy, World Food Programme. Retrieved on July17, 2013 from http://www.wfp.org/sites/default/files/Nutrition\%20Strategy_Final_high\%20res_5.pdf

Neyestani, T., Dadkhah-Piraghaj, M., Homa Haydari, H., Zowghi, T., Nikooyeh, B., Houshyar-Rad, A., Nematy, M., \& Maddah, M. (2010). Nutritional status of the Iranian children with physical disability: a cross-sectional study, Asia Pacific Journal of Clinical Nutrition, 19 (2), 223-230.

Odding, E., Roebroeck, M. E., \& Stam, H. J. (2006). The epidemiology of cerebral palsy: incidence, impairments and risk factors. Disability \& Rehabilitation, 28(4), 183-191. Retrieved on January, 2014 from http://informahealthcare.com/doi/abs/10.1080/09638280500158422

Palisano, R., Rosenbaum, P., Walter, S., Russell, D., Wood, E., \& Galuppi, B. (1997). Gross Motor Function Classification System, Dev Med Child Neurology, 39, 214-223. Retrieved on January 8, 2014 from http://www.canchild.ca/en/aboutcanchild/resources/GMFCS.pdf on 8th January, 2014.

Reilly, S., Skuse, D., \& Poblete, X. (1996). Prevalence of feeding problems and oral motor dysfunction in children with cerebral palsy: a community survey. The Journal of pediatrics, 129(6), 877-882. Retrieved on January 9, 2014 from http://www.sciencedirect.com/ science/ article/ pii/S002234769670032X

Rosenbaum, P., Paneth, N., Leviton, A., Goldstein, M., Bax, M., Damiano, D., ... \& Jacobsson, B. (2007). A report: the definition and classification of cerebral palsy April 2006. Dev Med Child NeurolSuppl, 109(suppl 109), 8-14. Retrieved on January 9, 2014 from http://onlinelibrary.wiley.com/ doi/10.1111/j.1469-8749.2007.tb12610.x/pdf

Saha, K. K., Frongillo, E.A., Alam, D. S., Arefeen, S. E., Persson, L.A., \& Rasmussen, K.M. (2008).Apropriate infant-feeding practices result in better growth of infants and young children in rural Bangladesh, American Journal of Clinical Nutrition, 87, 1852-9. Retrieved on August 17, 2013 from http://www.ncbi.nlm.nih.gov/pubmed/18541577 
Sánchez-Lastres, J., Eirís-Puñal, J., Otero-Cepeda, J.L., Pavón-Belinchón, P., \& Castro-Gago, M. (2003). Nutritional status of mentally retarded children in north-west Spain. I. Anthropometric indicators, Acta Paediatr, 92(6), 747-53. Retrieved on August 17, 2013 from http://www.ncbi.nlm.nih.gov/pubmed/12856990

Shabayek, M. M. (2004). Assessment of the nutritional status of children with special needs in Alexandria. Part II: Anthropometric measures, Journal Egypt Public Health Association. 79(56), 363-82. Retrieved on July 2, 2013 from http://www.ncbi.nlm.nih.gov/pubmed/17265606

Shekar, M, Heaver R, \& Lee Y. K. (2006). Repositioning nutrition as central to development : a strategy for large scale action. Washington, DC: World Bank, p. 246 . Retrieved on September 1,2013 from http://siteresources.worldbank.org/NUTRITION/Resources/2818461131636806329/ NutritionStrategy.pdf

Sullivan, P. B., Lambert, B., Rose, M., Ford-Adams, M., Johnson, A., \& Griffiths, P. (2000). Prevalence and severity of feeding and nutritional problems in children with neurological impairment: Oxford Feeding Study. Developmental medicine \& Child neurology, 42(10), 674680. Retrieved on January 9, 2014 from http://onlinelibrary.wiley.com/doi/10.1111/j.14698749.2000.tb00678.x/pdf

Tompsett, J., Yousafzai, A. K., \& Filteau, S. M. (1999). The nutritional status of disabled children in Nigeria: a cross-sectional survey, European Journal of Clinical Nutrition, 53, 915-919. Retrieved on June 8, 2013 from http://hinari-gw.who.int/whalecomwww.nature.com/ whalecom0/ ejcn/journal/v53/n12/index.html

UNICEF (2010), Nutrition in emergency unit, IFE Core Group. Retrieved on June 8, 2013 from http://www.unicef.org/nutrition/training/5.3.1/1.html

UNICEF. (2013). Disabilities: Nutrition. Retrieved on June 8, 2013 from http://www.unicef.org/ disabilities/index_65943.html

Victora, C.G., Adair, L., Fall, C., Hallal, P.C., Martorell, R., Richter, L., \& Sachdev, H.S. (2008). Maternal and child undernutrition: consequences for adult health and human capital, The Lancet, Volume 371, Issue 9609, P. 340 - 357, doi:10.1016/S0140-6736(07)61692-4, retrieved on August 17, 2013 from http://www.thelancet.com/journals/lancet/article/PIIS01406736(07)61692-4/fulltext

WHO/World Bank. (2011). World Report on Disability. Geneva. Retrieved on July 11, 2013 from http://www.who.int/disabilities/world_report/2011/report.pdf

Yousafzai, A. K., Filteau, S., \& Wirz, S. (2003). Feeding difficulties in disabled children leads to malnutrition: experience in an Indian slum, British Journal of Nutrition, 90(6):1097-106. Retrieved on July 11, 2013 from http://www.ncbi.nlm.nih.gov/pubmed/14641969 
